\title{
Contrapunteo de la cultura de las humanidades y los estudios de la cultura
}

\author{
Comparison between Culture in Human Sciences and in Cultural Studies \\ Contraponto entre cultura das humanidades e estudos da cultura
}

\section{Mónica Bernabé}

UNIVERSIDAD NACIONAL DE ROSARIO, ARGENTINA

Profesora titular de Literatura Iberoamericana II en la Escuela de Letras de la Facultad de Humanidades y Artes de la Universidad Nacional de Rosario. Doctora en Letras por la Universidad de Buenos Aires. Coordinadora Académica de la Maestría en Estudios Culturales (CEIUNR). Publicó Vidas de artista. Bohemia y dandismo en Mariátegui, Valdelomar y Eguren (Beatriz Viterbo-Instituto de Estudios Peruanos, 2006), El abrigo de aire. Ensayos sobre literatura cubana (Beatriz Viterbo, 2001; en colaboración con Antonio José Ponte y Marcela Zanin) y artículos y ensayos en volúmenes colectivos y revistas académicas. Correo electrónico: monicabernabeo2@gmail.com

Artículo de reflexión

Documento accesible en línea desde la siguiente dirección: http://revistas.javeriana.edu.co

Este trabajo fue leído en el Encuentro La Cultura Desde el Enfoque Interdisciplinario, que fue organizado por el Centro de Investigación y Documentación (CIDOC) de la Facultad de Comunicaciones y Humanidades de la Universidad Finis Terrae de Santiago de Chile, y que se llevó a cabo el 14 de abril de 2016. 


\section{Resumen}

Cuando han caído las viejas certezas de la cultura de las humanidades (las de la ciudadanía cultural, las del poder igualador de la educación popular, las de la integración republicana a través del voto universal) y cuando los estudios de la cultura se extravían entre nociones teóricas excesivamente abstractas y deslocalizantes, se hace necesario revisar algunos recorridos latinoamericanos que transgredieron las fronteras que se alzaban entre la ciencia, la crítica cultural y la literatura. Tal vez la etnografía ofrezca una clave interpretativa de interés para pensar la relación que existe entre las humanidades y los estudios de la cultura desde la segunda mitad del siglo XX.

Palabras clave: contrapunteo; humanidades; cultura; literatura; etnografía; literatura latinoamericana

\section{Abstract}

When the old certainties of the culture of the humanities have fallen (those of cultural citizenship, the equalizing power of popular education, the republican integration through the universal vote), and when cultural studies become lost in excessively abstract and delocalizing theoretical notions, it becomes necessary to review some Latin American journeys that transgressed the borderlines between science, cultural criticism, and literature. Perhaps the ethnography offers a relevant interpretive key to think the relationship between humanities and cultural studies from and onwards the second half of the 20th century.

Keywords: comparison; humanities; culure; literature; ethnography; Latin American literature

\section{Resumo}

Agora que caíram as velhas certezas da cultura das humanidades (as da cidadania cultural, do poder igualador do ensino popular, da integração republicana através do voto universal) e que os estudos da cultura extraviaram-se entre noções teóricas excessivamente abstratas e deslocalizantes, faz-se necessário rever alguns decorridos latinoamericanos que transgrediram as fronteiras entre ciência, crítica cultural e literatura. Talvez a etnografia ofereça uma chave interpretativa de interesse para pensar a relação entre humanidades e estudos da cultura desde a segunda metade do século XX.

Palavras-chave: contraponto; humanidades; cultura; literatura; etnografia; literatura latinoamericana

\section{Cómo citar este artículo:}

Bernabé, Mónica. "Contrapunteo de la cultura de las humanidades y los estudios de la cultura". Cuadernos de Literatura 21.41 (2017): 68-78. https://doi.org/10.11144/Javeriana.cl21-41.cche 
Guando LOS ESTUdios de la cultura no aciertan en las soluciones a los problemas acuciantes, cuando se han derrumbado nociones como las de sociedad, clase o nación, cuando las disciplinas que compartimentaron los saberes modernos resultan insuficientes, lo que queda es la pregunta. Así imagina García Canclini la tarea del investigador en El mundo entero como lugar extraño; tan extraño como la estructura misma del libro en el que un reconocido académico actúa burlonamente como etnógrafo de sí mismo, y asiste a congresos y mesas redondas sin ánimos de intervenir, sino solo para observar las prácticas que se desarrollan en los espacios en donde interactúan sus colegas.

Ya no existen las respuestas salvadoras, y Edipo vence a la Esfinge con la potencia de una interrogación mayor. Si la posmodernidad había declarado la obsolecencia del Sabelotodo que supo compendiar de la A a la Z, los rudimentos básicos con los que salir airoso de las justas del saber, ahora el académico de García Canclini descubre que las nociones hiperexplotadas de nomadismo, frontería y desterritorialización se han vuelto ineficaces abstracciones que terminan por idealizar "el poder liberador de cualquier deslocalización" (51). En la entrada al reino de incertezas que configuran los nuevos territorios de la producción de conocimiento en las ciencias sociales y humanas, sostener la pregunta sobre el límite de las disciplinas puede dar curso a un buen programa de trabajo fuera de las lógicas y protocolos académicos que por temor a lo desconocido se atrincheran en la línea de autoconservación.

En estos escenarios contemporáneos montados para la duda, cabe preguntar entonces: ¿qué ha quedado de las viejas creencias de la utopía americana?, ¿qué perdura, en el campo de las humanidades, del ethos pedagógico desde donde se constituyeron los programas de estudio del latinoamericanismo clásico? Invocando a Platón, a comienzos del siglo XX, el dominicano Pedro Henríquez Ureña dio rienda suelta a la imaginación, propiciando la invención de una identidad común para unir a América a partir del culto a la tradición helénica y la fe en la educación de las masas. Es la misma senda que muy tempranamente había abierto en Chile Andrés Bello, y a la que se sumaron José Enrique Rodó, Alfonso Reyes, Mariano Picón Sala y Ricardo Rojas, para trabajar por la institucionalizacón de los estudios humanísticos y producir las ficciones maestras de integración nacional y continental. Como apuntó Julio Ramos, fueron ellos los que diseñaron el orden pedagógico e imaginaron los sujetos didácticos de la nación.

"La cultura de las humanidades": así tituló Henríquez Ureña la conferencia inaugural que presentó en la Escuela de Altos Estudios de la Universidad Nacional de México en el año de 1914. Ella suponía que la unidad armónica de la enseñanza de la filosofía, los estudios literarios, las artes plásticas y la música, 
en la creencia de que el milagro helénico podía renacer en América Latina, serviría para legitimar un campo de acción y darle organización formal a los estudios superiores. En la alta cultura también se gestionaba un lugar de enunciación para un sujeto social proveniente de los sectores medios en ascenso, y un nuevo tipo de autoridad asentada en una actividad profesional diferente a la de los letrados tradicionales.

En el núcleo central de la genealogía de los estudios humanísticos se encuentra la idea de utopía de Henríquez Ureña, que asociaba el futuro con un sentido estético. En procura de la homogeneización cultural, étnica, sexual y lingüística, los proyectos pedagógicos imbuídos de la retórica del americanismo asumieron la tarea de formación de los tan deseados ciudadanos. Aquellos serían resultado de la suma del espirituralismo aristocrático arielista y la grandilocuencia del nacionalismo; dos elementos imprescindibles para dar batalla cultural al amenazante modelo utilitarista que guiaba a los hombres de Estado. La utopía también pretendía formar a sus aristos en el ocio helénico frente a la tiranía del neg-ocio con la que se figuraba al otro anglosajón. Se trató, como dijo el filósofo argentino Oscar Terán, del primer antiimperialismo latinoamericano: una aspiración al desarrollo con justicia social forjada junto con el desinterés de la alta cultura.

Por más de medio siglo, en América Latina los intelectuales gestionaron la vinculación del estudio de las humanidades y el aparato estatal, aunque sin descuidar la relación con el mercado editorial emergente. En política de publicaciones, el caso de Henríquez Ureña también es emblemático: organizó las colecciones Cien obras maestras y Grandes escritores de América para Losada, y diseñó la Biblioteca Americana para el Fondo de Cultura Económica. Así, ofreció un programa de lecturas de obras maestras; joyas de la literatura por medio de las que los maestros y profesores podían desarrollar tanto el buen gusto y el sentido estético, como el uso correcto del idioma con los fines de ejercer el control lingüístico. En las tareas de vigilar el uso correcto de la lengua y castigar las faltas, se aseguraba la pureza del buen decir, libre de las corrosiones, y los usos espúreos de la palabra.

¿Cuándo fue que comenzó a quebrarse la autoridad de la cultura de las humanidades?, ¿cuándo cedió aquella fe en la potencia igualadora de la alta cultura? En el momento en que el campo de batalla cultural se trasladó de la escuela y las instituciones de enseñanza superior a la televisión y los medios de comunicación; cuando la producción cultural pasó a formar parte importante del PBI de las naciones, y la antropología y la sociología alteraron hondamente los modos de pensar la cultura; cuando las cuestiones de género perfilaron la emergencia de nuevas subjetividades: en aquel momento la cultura de las humanidades perdió 
su lugar rector. Así, en los sesenta se abre un largo proceso de reconversión que cuestiona la autonomía de las disciplinas y las ficciones de integración nacional elaboradas en sintonía con los deseos universalizantes del poder letrado.

Hoy trabajamos con las ruinas de la utopía americana, que es lo mismo que obrar con la caída a pique de las viejas certezas: las de la ciudadanía cultural, las del poder igualador de la educación popular, las de la integración republicana a través del voto universal. ¿Qué hacer, entonces, con la experiencia de ajenidad extrema que se vivencia más allá de las burbujas académicas? Si la tecnología, que protagonizó la única revolución triunfante del siglo $\mathrm{XX}$, ha transformado definitivamente nuestras prácticas cotidianas, ¿qué puede hacer la cultura en una región en donde la desigualdad económica sigue siendo la más apremiante de todas regiones del planeta: en 2004 el consumo del quintil (20\%) más pobre de la población sólo representaba el 2,7\% del consumo nacional.

Atendiendo al rodeo sigiloso con que el académico de García Canclini acude a aquellos lugares en donde podría atisbarse una respuesta, me limito a señalar un texto entre los miles de papeles que hablan del fin de la utopía. Uno de Ángel Rama: "La riesgosa navegación del escritor exiliado", que fue publicado entre marzo y abril de 1978 en Caracas. Rama había llegado a Venezuela en 1972 para dar un curso en la Escuela de Letras de la Universidad Central, y allí lo sorprendió el golpe militar uruguayo del 27 de junio de 1973: un acontecimiento que le ocasionó una serie de turbulencias económicas y laborales. En el texto, publicado en la revista $\mathcal{N}$ ueva Sociedad, también se enuncian las tristes circunstancias en que un académico, practicando una sesgada forma de autoetnografía, se da la tarea de derumbar la jerárquica y aristocratizante distinción entre exiliado y emigrante:

Los intelectuales exiliados... son integrantes de un estrato social y educativo que se mueve junto con enteras poblaciones. Existe en América Latina, más en algunas zonas que en otras, un verdadero pueblo en diáspora, compuesto de los más diversos elementos, desde la mayoría de obreros, campesinos y trabajadores manuales hasta equipos profesionales que se desplazan[.] (96)

El autor recuerda a los pescadores y trabajadores cubanos de Tampa que le dieron apoyo material y personal a José Martí para iniciar la guerra de la independencia desde el exilio de los EE.UU.:

Estos pueblos de la diáspora son sometidos a vertiginosos procesos de transculturación, a experiencias sociales violentas y a rudas mutaciones. Estos cambios que han sido abundantemente descritos para las migraciones internas que trasladan a las poblaciones rurales a los barrios periféricos y miserables de las capitales latinoamericanas (las barriadas de Lima y de México, 
los cerros de Caracas, las favelas de Río de Janeiro) también se ejercen sobre las migraciones externas, con el agregado del pasaje a culturas y sistemas de vida aún más remotos y distantes: son los jornaleros mexicanos que se instalan en la periferia de los Ángeles, o los campesinos colombianos que ingresan a Maracaibo o Caracas, los trabajadores paraguayos que se suman a Buenos Aires. Para medir los cambios hay que comenzar por reconocer que la pregonada unidad de América Latina, que es un latiguillo retórico de los intelectuales desde los orígenes independientes, esconde una multiplicidad de culturas tan variadas como las europeas, no empece el manejo, solo aparencial, de la misma lengua, en toda la zona hispanohablante. (97)

Por los años de exilio, Rama desarrolló dos proyectos, publicados en los ochenta bajo los títulos Transculturación narrativa en América Latina y La ciudad letrada, en los que produjo el giro transdisciplinario que hoy alentamos en nuestros programas de estudio. A estas investigaciones hay que sumar el conocimiento del pasado intelectual y literario que le proporcionó la tarea de editor de la Biblioteca Ayacucho en Caracas.

La noción misma de transculturación fue forjada en el inédito vínculo de Fernando Ortiz con José María Arguedas; dos escritores atípicos que escribieron sobre las peculiaridades culturales del Caribe y del área andina, luego de realizar intensas experiencias etnográficas. Rama formuló estrategias para pensar las relaciones existentes entre literatura y sociedad a partir de la apertura del canon a productos culturales tan heterogéneos como las versiones latinoamericanas del musical Hair, que analiza junto a los relatos orales del tucâno Tomalãn Kenhíri y los problemas de traducción que surgieron cuando fueron trasladados del desâna al portugués. Por esos años, Rama también se dedica a estudiar alemán para leer a Benjamin en su lengua original, tan apasionadamente como leía a Foucault y $\mathrm{El}$ antiedipo de Deleuze y Guattari, apropiándose muy sutilmente de esas aportaciones teóricas, y de este modo, poder revisar la herencia del estrucuturalismo que él mismo había incorporado a través de Levi-Strauss. Rama practicó lo que podríamos denominar una teoría-crítica transcultural, cruzando autores y fronteras para impugnar el estado de la crítica literaria de su tiempo desde una propuesta transdisciplinaria que hoy irradia hacia los programas institucionales dedicados al estudio de la cultura en el marco de las viejas estructuras de las humanidades.

Del legado intelectual de Rama se desprende una serie de postulados que tal vez puedan oficiar de guía para profundizar e institucionalizar proyectos intelectuales interdisciplinarios, al tiempo que den alerta sobre los riesgos y tensiones por los que esos estudios actualmente atraviesan. 


\section{La textualidad no es todo}

A mediados de los ochenta, cuando recién comenzábamos con nuestra tarea, leyendo a Rama pudimos sortear los riesgos del telquelismo y del exclusivismo de la conexión francesa que reinaba en la academia argentina. Sin embargo, aún hoy se puede advertir que en general leemos procesos de significación textual olvidándonos fácilmente de la contextualización, entendida como la articulación compleja entre discursos, vida cotidiana, imaginarios y tecnologías.

\section{¡Salgamos de la biblioteca!}

La biblioteca, entendida por su parte como un corpus organizado de nuestra tradición, se tensa con el archivo, mundo oscuro y dominante que Borges prefiguró en "La biblioteca de Babel", y que Foucault teorizó como la ley de lo que puede ser dicho; es decir, el sistema que rige la aparición de los enunciados como acontecimientos singulares. Tal vez, lo que hoy entendemos por archivo sea la realización de la fórmula que lanzó Blanchot hacia fines de los años treinta: "Ya no existe biblioteca, a partir de ahora, cada cual leerá a su aire" (113). El archivo le impone a la biblioteca un desvío: Arguedas, en su obra narrativa y ensayística, y Fernando Ortiz, en su trabajo sobre la cultura cubana, demostraron que no hay en el archivo un criterio de selección que diga que hay textos que merecen estar en él y otros que no tienen la dignidad suficiente como para estar ahí. Ya hace tiempo que el libro convive, dialoga y converge con otros soportes del archivo audiovisual, desjerarquizando la aristocrática biblioteca de las humanidades.

\section{Inventamos y erramos}

La voz mítica de don Simón Rodríguez ha sido usada y abusada hasta el hartazgo por el declaracionismo político. Sin embargo - en estas tristes circunstancias post-utópicas - solicita ser reactivada con pequeñas modificaciones (la $y$ por la o) con fines metodológicos. ¿Cuál sería el método de la interdisciplina? A mitad de camino entre el arte y la ciencia, sin querer forzar las categorías ni ampararnos en genealogías que legitimen nuestra posición, acudimos a ejemplos que, como formas residuales, contribuyen al desvanecimiento de la lógica de los campos autónomos de las disciplinas. Bastará con releer algún fragmento de La música en Cuba de Alejo Carpentier para dar con un método de trabajo válido en el campo expandido de las investigaciones interdisciplinares. El libro, producto de una investigación de archivo combinada con un trabajo etnográfico, es muy próximo en su aspecto a la forma en que hoy se presentan los estudios de la cultura, aunque se desarrolló sin la mediación de un programa académico y más bien con el ánimo de intervenir en los debates públicos. Carpentier, como Ortiz 
y Arguedas, escribió en la confluencia del archivo con la observación rigurosa de las prácticas confusas de su tiempo. Fue así que el género ensayo se le ofreció, a él al igual que a los otros dos autores citados, como una suerte de laboratorio para una investigación que cruzaba fronteras sin pedir permisos a las autoridades académicas ni a los organismos de financiamiento que regulaban los protocolos de las ciencias sociales. Sin pretender salvar ni achicar distancias, cabe preguntar si existe alguna afinidad entre los estudios de la cultura de mediados de siglo $\mathrm{XX}$ con el desdibujamiento actual del pensamiento en las esferas más o menos delimitadas de lo político, lo económico y lo cultural, tal como postula Josefina Ludmer. ¿Serán formas diversas de politizar la teoría?

\section{¡A contrapuntear, a contrapuntear!}

La indagación en simultáneo de la relación existente entre las culturas hegemónicas y las topografías distintivas que dibujan las culturas alternativas, será eficaz en la medida en que al citar a Edward Said cuando propone al contrapunto como método de análisis en el marco de colonialidad, no olvidemos contrapuntearlo con el cubano Fernando Ortiz y sus análisis de la cultura en el Caribe. La cuestión del método no es un asunto menor: observaciones etnográficas, historias de vida, autobiografías, trabajos de campo, permiten ingresar al archivo series diversas de prácticas, escamoteos, negociaciones y relaciones que necesariamente modificarán el corpus con el que habitualmente trabajamos. La interdisciplina es experimentación y riesgo: resulta atractivo aventurarse en diálogos con los que especulan con la teoría estética, o con los que hacen investigación empírica y analizan datos, porque probablemente entraremos en la zona en donde las preguntas se reformulan. En la zona de promesas, para decirlo con la canción de Cerati.

\section{¿Interdisciplina o transdisciplina?}

¿Estudios culturales o estudios de la cultura? ¿Crítica cultural o sociología de la cultura? ¿Teoría crítica o ensayismo de interpretación? ¿ ¿Intervención política o distanciamiento crítico? ¿Rigor teórico o relativismo epistémico? Los dilemas podrían seguir aunque probablemente no hallarán respuesta en lo inmediato. Stuart Hall recuerda que en el Centro de Birminghan iban construyendo objetos de estudio y resolviendo formas de abordaje en la medida en que trabajaban. Así, todos se declaraban aprendices. La imagen de una "comunidad de hablantes" provenientes de diferentes disciplinas es feliz, aunque corramos el riesgo de reponer la utopía. Para sortear el peligro, añadimos la acción de recorrer: "Recorrimos las disciplinas", dice Hall (22). En ese contexto, me inclino por el prefijo trans-: al otro lado, a través de, traslado, traspaso, pasaje, tránsito, movimiento; 
en definitiva, la partícula promueve la acción de caminar, de flanear por diversas disciplinas, sin demasiados compromisos con cada una de ellas, aunque con la atención flotante que todo asunto serio se merece. La transdisciplina es una aspiración; un deseo de articular conocimientos en una conversación que siempre será inconclusa.

\section{La paradójica historia del Sr. Murdock}

Para terminar quiero referirme a un brevísimo relato de Borges: "El etnógrafo", que fue publicado en 1969 en Elogio de la sombra (el mismo año en que Arguedas se suicida, poniendo fin a un relato radical de la transculturación como lo es $E l$ zorro de arriba y el zorro de abajo). Borges cuenta la historia de Fred Murdock, un estudiante universitario norteamericano a quien su profesor le aconseja estudiar lenguas indígenas y vivir por un tiempo entre los nativos de una tribu del oeste de los EE.UU., para observar sus ritos esotéricos de modo que pueda descubrir el secreto que los brujos revelan al iniciado. De vuelta, dice el profesor, Murdock podría redactar la tesis y publicar sus resultados en la imprenta de la universidad. Luego de dos años de convivir entre los hombres rojos, Murdock retorna a la universidad para comunicarle a su profesor que tenía el secreto y que el valor del secreto sobrepasaba largamente a la ciencia que a sus ojos se había vuelto una mera frivolidad. Pero más que el secreto, de por sí precioso, valían los caminos que lo habían conducido. Murdock decidió no volver a la tribu ni escribir la tesis. Finalmente, terminó trabajando como bibliotecario de Yale.

El silencio de Murdock es equivalente a una negación de la traducción. Se niega la transferencia del secreto de una cultura dominada a la lengua de la cultura dominante. Revelar el secreto de los brujos indígenas implicaría una forma de sometimiento a la que Murdock decide no plegarse. Rechaza, en definitiva, la posibilidad de la transculturación. Podríamos interpretar, en una primera lectura, que Murdock resiste a la traición con la que se suele asociar a la traducción, tal como reza el viejo proverbio italiano: traduttore, traditore. Sin embargo, como sucede habitualmente, los relatos de Borges despliegan paradojas que logran descolocar la linealidad de la primera lectura. El relato sorprende por los efectos especulares que produce: entre los indios, Murdock aprendió a despojarse de la ropa, las costumbres y las prácticas occidentales; particularmente, interesa que rompió sus notas y abandonó la escritura. De regreso a la cultura desde donde había partido y a la que pertenecía, siguió operando con los códigos aprendidos entre los indios; de hecho, se negó a escribir su tesis. Sin embargo, y paradójicamente, se ocupa de los libros: se vuelve bibliotecario, custodio del tesoro, de los objetos de máximo valor para la cultura letrada. 
En el relato de Borges no hay intercambio posible, pero hay donación. En el ritual del pasaje, el secreto de una cultura queda alojado en el centro mismo de la otra. Es el secreto lo que se traslada, pero resistiendo a la revelación. La narración de Borges pone en escena un caso extremo y paradójico de la relación: la desmaterialización absoluta de la cultura, exponiendo a la literatura misma a un grado máximo de negatividad. Murdock, como el Bartleby de Melville, prefirió no hacerlo: no escribir, no recibirse, no formar parte de la comunidad científica a la que estaba destinado. De un lado y del otro, Murdock es un extranjero. Y en esa no revelación, en esa decisión de ser incluido (porque vuelve a la universidad) pero afuera (porque no se recibe de antropólogo, queda como bibliotecario), denuncia la frívola pretensión de reducir la cultura de los otros a la simple abstracción de una tesis.

¿Qué hace Murdock en la biblioteca? ¿Entrevió tal vez que su narrativa etnográfica y su trabajo de campo terminarían formando parte de la nada que es la literatura? Aquí podemos arrojar una hipótesis: el estudio de la cultura es un relato de los modos de hacer que trabaja en los instersticios; en una zona de frontera que exige el traslado, el ir y venir entre disciplinas tanto como transitar por el límite difuso que separa a la ciencia de la literatura, ahora más que nunca, cuando todas las respuestas solo pueden ser provisorias.

\section{Obras citadas}

Arguedas, José María. Formación de una cultura nacional indoamericana. Selección y Prólogo de Ángel Rama. Buenos Aires: Siglo XXI editores, 1987. Impreso.

Arguedas, José María. El zorro de arriba y el zorro de abajo. Coord.

Eve-Marie Fell. Madrid: CSIC, 199o. Impreso.

Blanchot, Maurice: Tiempo después precedido por La eterna reiteración. Trad.

Rocío Martínez Ranedo. Madrid: Arena Libros, 2003. Impreso.

Borges, Jorge Luis. Obras completas. Buenos Aires: Emecé, 1974. Impreso.

Carpentier, Alejo. La música en Cuba. México: Fondo

de Cultura Económica, 1945. Impreso.

Foucault, Michel. La arqueología del saber. Trad. Aurelio Garzón

del Camino. Buenos Aires: Siglo XXI, 1970. Impreso.

García Canclini, Néstor. El mundo entero como lugar extraño.

Buenos Aires: Gedisa, 2014. Impreso.

Hall, Stuart. "El surgimiento de los estudios culturales y la crisis de las humanidades". Sin garantías. Lima: IEP, 2010. 17-28. Impreso.

Henríquez Ureña, Pedro. "La cultura de las humanidades" en La utopía de América. Caracas: Biblioteca Ayacucho, 1978. 56-64. Impreso. 
Ludmer, Josefina. Aquí América Latina. Una especulación.

Buenos Aires: Eterna Cadencia, 2010. Impreso.

Ortiz, Fernando. Contrapunteo del tabaco y el azúcar. La Habana:

Editorial de Ciencias Sociales, 1991. Impreso.

Rama, Ángel. "La riesgosa navegación del escritor exiliado". Nueva sociedad 35 (marzo-abril de 1978): 95-105. Impreso.

Rama, Ángel. Transculturación narrativa en América

Latina. México: Siglo XXI, 1982. Impreso.

Rama, Ángel. La ciudad letrada. Hanover: Ediciones del Norte, 1984. Impreso.

Ramos, Julio. "El proceso de Alberto Mendoza: paradojas de la subjetivación". Asedios a la heterogeneidad cultural. Libro de Homenaje a Antonio Cornejo Polar. Coords. José Antonio Mazzotti y Juan Zevallos Aguilar. Lima: Asociación Internacional de Peruanistas, 1996. 431-454. Impreso.

Said, Edward. Cultura e imperialismo. Barcelona: Anagrama, 1996. Impreso.

Terán, Oscar. "El primer antiimperialismo latinoamericano". En busca de la ideología argentina. Buenos Aires: Catálogos, 1986. Impreso.

Unesco. "Panorama Regional América Latina y el Caribe". es.unesco.

org. Unesco. Web. 12 de abril de 2016. <http://es.unesco.org/

gem-report/sites/gem-report/files/157271S.pdf> 